\title{
Moderate mental illness as a predictor of chronic disease prevention and screening
}

\author{
Ginetta Salvalaggio * (D), Christopher Meaney, Rahim Moineddin, Eva Grunfeld and Donna Manca
}

\begin{abstract}
Background: Primary care plays a pivotal role in the provision of both mental health care and chronic disease prevention and screening (CDPS). Unfortunately, moderate mental illness (MMI) is associated with poorer general health outcomes. Part of this burden of illness may be due to reduced CDPS uptake. The Building on the Existing Tools to Improve Chronic Disease Prevention in Primary Care (BETTER) trial recruited 777 participants ages 40-65 from 32 family practice panels, of whom 135 (18.2\%) had elevated GAD scores, 118 (16.4\%) had elevated PHQ scores, and 264 (34.0\%) had electronic medical record (EMR)-documented MMI. We hypothesized that patients with screen-positive or chart-documented MMI are 1) eligible for more CDPS actions, and 2) able to complete a lower proportion of CDPS actions than patients unaffected by MMI.

Methods: This study was a secondary analysis of data from the BETTER trial. Participants were stratified by both EMR-documented MMI and screen-positive evidence of MMI (using the General Anxiety Disorders (GAD-7) and Patient Health Questionnaire (PHQ-9) instruments for anxiety and depression screening, respectively). The primary outcome was the proportion of CDPS actions for which the patient was eligible completed at follow-up, using a composite index.

Results: After adjusting for age, gender, and social support, patients with evidence of MMI had a lower composite index than patients without evidence of $\mathrm{MMI}(p<0.05)$. The lower composite index is primarily due to higher eligibility for CDPS at baseline; ability to complete CDPS was not statistically different.

Conclusions: Patients affected by MMI are eligible for more CDPS actions than their unaffected counterparts. Although they are able to complete a similar number of CDPS actions, they are not able to eliminate their baseline CDPS gap. Primary care teams need to be aware of this increased CDPS eligibility for patients with MMI and ensure best practices in CDPS supports are available to this patient population. Further study is needed to determine the ideal suite of targeted supports.
\end{abstract}

Keywords: Primary care, Family practice, Chronic disease prevention, Screening, Depression, Anxiety

\section{Background}

Primary care plays a significant role in the provision of mental health care [1]. Often, family physicians are the initial point of contact for moderate mental illness (MMI) such as anxiety and depression [2]. In addition, treatment of these mental health concerns is usually provided without the assistance of a specialist provider [3-5]. Primary care physicians are also responsible for the management of chronic nonpsychiatric illness and preventive health; it can be difficult to address all chronic medical issues and preventive health actions in

\footnotetext{
* Correspondence: ginetta@ualberta.ca

Ginetta Salvalaggio, University of Alberta, Edmonton, Canada
}

traditional family practice visits [6-9]. MMI is commonly associated with higher social complexity, including reduced health literacy, lack of child care or transportation, low income, and unstable or unsafe living environments [10-12]. These factors can impede patients' ability to complete labwork or eat and exercise according to preventive care guidelines [11-13]. Often, the most pressing issues during any visit to a primary care team are managed, and other issues may be delayed until a subsequent appointment. Issues delayed to another appointment may never be adequately addressed and chronic disease prevention and screening (CDPS) can easily be lost among these other priorities $[8,9,14]$. 
Literature suggests that adherence to guideline based CDPS actions is not equal among different populations. Patients living with low socioeconomic position, addiction, and/or mental illness are disadvantaged with respect to CDPS, completing a lower number of screening actions compared to the general population $[15,16]$. It could also be hypothesized that poorer health outcomes in these groups may be accounted for in part by reduced CDPS. Clinical practice guidelines for specific diseases acknowledge the association between mental and physical illness and encourage clinicians to screen for MMI in the presence of other chronic conditions [17]; however they do not address the converse (screening for chronic conditions in the presence of MMI). Few tools exist to support CDPS uptake for patients with MMI, and no rigorously studied interventions to improve CDPS uptake in this population have been published.

MMI is not uncommon in the primary care setting; a recent report from the World Health Organization found the prevalence of depression in primary care in various countries ranged from $5-20 \%$ and anxiety ranged from $4-15 \%$ [1]. In Canada, one study estimated that 1 in 5 Canadians are affected annually by MMI [18] and another identified that $14 \%$ of primary care patients had a diagnosis of depression [19]. Given the prevalence of MMI in primary care populations, it is particularly important to explore potential differences in CDPS uptake in these patients compared to those without MMI. The purpose of this study was to explore the relationship between eligibility for - and completion of CDPS - actions and MMI. Specifically, we investigated whether those patients with screen-positive or chart-documented MMI are eligible for more not-yet-completed CDPS actions compared to individuals without MMI. Further, we investigated whether those with MMI are able to accomplish CDPS actions for which they are eligible at a similar rate as their unaffected counterparts.

\section{Methods}

\section{Design, setting and patients}

To investigate differences in CDPS between patients with versus without MMI, this study used a subset of data from the Building on the Existing Tools to Improve Chronic Disease Prevention in Primary Care (BETTER) trial [20]. The BETTER trial was a pragmatic factorial randomized controlled trial conducted in eight primary care team practices in two Canadian cities (Toronto, Ontario and Edmonton, Alberta). Within each of the participating primary care teams were four primary care physicians. In total, 32 primary care physicians (and their patients) participated in the BETTER trial (16 from Toronto and 16 from Edmonton). Patients in the BETTER trial were limited to actively rostered patients between the ages of 40-65 (as most CDPS actions target individuals in this age range). The BETTER trial recruited patients based on information derived from the patients' electronic medical record. Patients were stratified into one of two groups: 1) without MMI and 2) with MMI. MMI was defined by attendance for a MMI diagnosis in the previous 12 months and documentation of 1) depression, anxiety, or pyschosomatic illness in two different places in the chart, 2) two different MMI diagnoses in the same charting field, or 3) one MMI diagnosis and one prescription for psychiatric medication. Forty-five randomly selected patients -25 without chartdocumented MMI, and 20 with chart-documented MMI-from each physician practice were invited to participate. Patients documented as unstable or with more severe mental illnesses such as schizophrenia and bipolar affective disorder were excluded from the study.

The survey that patients completed at baseline included the Generalized Anxiety Disorder 7-item scale (GAD-7) and the Patient Health Questionnaire (PHQ-9). Moderate anxiety is more likely with a GAD score greater or equal to 10 [21, 22]; moderate depression is more likely with a PHQ score greater or equal to 10 [23, 24]. Our research team considered the likelihood that a) some patients with chartdocumented MMI ("detected") may screen negative on both the GAD and PHQ ("inactive symptoms") as a result of disease remission, and b) some patients without chartdocumented MMI ("not detected") may screen positive on either the GAD or PHQ ("active symptoms") due to undetected illness or lack of documentation. In theory, patients with clinically active symptoms would have the highest burden of illness, hence those with both chartdocumented and screen-positive MMI would be the most affected by their condition and least able to carry out recommended CDPS actions, followed by patients with chartdocumented MMI only, with screen-positive but undiagnosed patients least affected of these three groups and most able to achieve CDPS actions. Thus, for the purposes of this analysis, we stratified BETTER trial participants into four groups: 1) detected / active symptoms; 2) detected / inactive symptoms; 3 ) not detected / active symptoms; and 4) not detected / inactive symptoms ("unaffected").

\section{Outcome measures}

The primary outcome of the BETTER trial was a composite endpoint of the proportion of eligible CDPS actions for which patients were eligible at baseline (denominator), achieved at follow-up (numerator). This outcome, a composite index, was modeled after the Summary QUality InDex (SQUID) introduced by Nietert [25]. The 28 items in the composite related to primary prevention and screening for diabetes, cardiovascular disease and cancer, as well as the promotion of a healthy lifestyle (diet, exercise, weight management, smoking, alcohol), supported by clinical practice guidelines [17]. 
Table 1 Stratification of patients by screen-positive and chart-documented evidence of MMI

\begin{tabular}{llll}
\hline & Active Symptoms & Inactive Symptoms & \\
\hline Detected & $13 \%(99)$ EMR + / Screen + & $21 \%(161)$ EMR + / Screen - & $34 \%(260)$ Detected \\
Not Detected & $10 \%(75)$ EMR - / Screen + & $56 \%(425)$ EMR - / Screen - & $66 \%(500)$ Not Detected \\
& $23 \%(174)$ Active & $77 \%(586)$ Inactive & $100 \%(760)$ Total \\
\hline
\end{tabular}

Precise operational definitions of each of the 28 components of the composite endpoint can be found in the article describing the BETTER trial outcomes [20]. At baseline, each patient was assessed to determine (through use of a patient self-report survey and the patient's electronic medical record (EMR)) their eligibility for each of the 28 components under consideration. Patients were followed prospectively from baseline for six months, at which time actual completion of each action was reassessed.

\section{Statistical analysis}

Descriptive summaries of the data are presented as means and standard deviations for continuous variables; counts and percentages for categorical variables.

We compared our composite index outcome across discrete groups (i.e. the mental health indicator), using a non-parametric Kruskal-Wallis test; we also used generalized estimating equation (GEE) models to adjust for the design effect of patients being clustered within physicians. We present two variations of the GEE model;

Table 2 Characteristics of patients by baseline screen-positive (GAD-7/PHQ-9) and chart-documented MMI ${ }^{\mathrm{a}}$

\begin{tabular}{|c|c|c|c|c|c|}
\hline & \multicolumn{4}{|c|}{ Composite Covariate (GAD, PHQ, BETTER MMI) } & \multirow[b]{2}{*}{$P$-value } \\
\hline & $\begin{array}{l}\text { Not Detected / Inactive Symptoms } \\
\text { (Unaffected, } N=425 \text { ) }\end{array}$ & $\begin{array}{l}\text { Detected / Inactive } \\
\text { Symptoms }(N=161)\end{array}$ & $\begin{array}{l}\text { Not Detected / Active } \\
\text { Symptoms }(N=75)\end{array}$ & $\begin{array}{l}\text { Detected / Active } \\
\text { Symptoms ( } N=99)\end{array}$ & \\
\hline Age (years) & $53.4(6.9)$ & $53.9(6.6)$ & $51.3(6.6)$ & $51.8(6.4)$ & 0.006 \\
\hline Female sex & $282(66.4)$ & $128(79.5)$ & $56(74.7)$ & $80(80.8)$ & 0.002 \\
\hline $\begin{array}{l}\text { Minority race or ethnic } \\
\text { group }\end{array}$ & $49(11.9)$ & $13(8.2)$ & $10(13.9)$ & $13(13.5)$ & 0.47 \\
\hline $\begin{array}{l}\geq 1 \text { yr. post-secondary } \\
\text { education }\end{array}$ & $377(89.1)$ & $130(80.8)$ & $65(87.8)$ & $77(77.8)$ & 0.006 \\
\hline $\begin{array}{l}\text { Full or Part-time } \\
\text { Employment }\end{array}$ & $334(79.0)$ & $124(77.0)$ & $60(81.1)$ & $54(55.7)$ & $<0.0001$ \\
\hline Married/common-law & $350(82.6)$ & $116(72.1)$ & $52(71.2)$ & $57(58.2)$ & $<0.0001$ \\
\hline \multicolumn{6}{|l|}{ Total Household Income } \\
\hline$\geq 100,000 \mathrm{CAD}$ & $236(58.4)$ & $76(47.8)$ & $32(43.8)$ & $28(29.8)$ & \multirow[t]{3}{*}{$<0.0001$} \\
\hline 60,000-99,999 CAD & $109(27.0)$ & $48(30.2)$ & $20(27.4)$ & $29(30.9)$ & \\
\hline $0-59,999$ CAD & $59(14.6)$ & $35(22.0)$ & $21(28.8)$ & $37(39.3)$ & \\
\hline Current smoker & $26(6.1)$ & $12(7.5)$ & $8(10.7)$ & $33(33.3)$ & $<0.0001$ \\
\hline \multicolumn{6}{|c|}{ Current alcohol consumption } \\
\hline$<4 \times$ per month & $260(61.3)$ & $105(65.2)$ & $52(71.2)$ & $72(73.4)$ & \multirow[t]{3}{*}{0.04} \\
\hline $\begin{array}{l}\geq 4 \times \text { per month } \\
\text { and }<2 \times \text { per week }\end{array}$ & $111(26.2)$ & $29(18.0)$ & $12(16.4)$ & $13(13.3)$ & \\
\hline$\geq 2 \times$ per week & $53(12.5)$ & $27(16.8)$ & $9(12.4)$ & $13(13.3)$ & \\
\hline \multicolumn{6}{|l|}{ Exercise status } \\
\hline Extremely active & $82(19.3)$ & $29(18.2)$ & $7(9.6)$ & $16(16.3)$ & \multirow[t]{2}{*}{0.24} \\
\hline$\leq$ Mildly active & $342(80.6)$ & $130(81.8)$ & $66(90.4)$ & $82(83.7)$ & \\
\hline Body-mass index & $24.9(4.9)$ & $25.3(5.2)$ & $26.5(5.5)$ & $26.8(5.8)$ & 0.004 \\
\hline Obese & $58(14.1)$ & $27(16.9)$ & $16(22.2)$ & $29(29.3)$ & 0.003 \\
\hline $\begin{array}{l}\text { MOS Social Support } \\
\text { Score }\end{array}$ & $83.4(18.3)$ & $75.2(23.3)$ & $60.7(27.1)$ & $55.4(28.6)$ & $<0.0001$ \\
\hline
\end{tabular}


the first, a bivariate GEE model using only the categorical grouping variable under consideration (i.e. the MMI indicator); and the second, a multivariate GEE model estimating the impact of the same categorical grouping variable on the composite index after adjusting for age, gender, and social support.

We considered individual components of the composite index related to smoking and alcohol as these behaviours are known to be more prevalent in populations affected by MMI [26-30]. As this analysis is exploratory, we only present counts and proportions corresponding to the number of patients eligible and achieving actions in each of the MMI groups.

All statistical analyses were conducted in SAS version 9.3 (Cary, North Carolina).

\section{Research ethics and trial registration}

The trial was approved by the Ontario Cancer Research Ethics Board (REB), University of Alberta REB, and all relevant REBs in each province and at each primary care team site. The registration number of the original RCT BETTER trial was ISRCTN07170460.

\section{Results}

The BETTER trial enrolled 789 patients. Twelve patients withdrew from the trial prior to completion and 777 patients were included in the analysis. Patients enrolled in the BETTER trial were ages 40-65, predominantly female, Caucasian, and well educated. A more detailed description of the trial participants can be found in Grunfeld et al. [20].

Of the patients with available scores, 18.2\% (135/742) had elevated GAD scores, 16.4\% (118/720) had elevated
PHQ scores, and 34.0\% (264/777) had chart-documented MMI, with significant overlap between those patients identified via screening and those identified through the medical record (Table 1). Of the 500 patients with available GAD and/or PHQ scores and without chartdocumented MMI, a total of $15.0 \%$ (75/500) screened positive for MMI as determined by the GAD and the PHQ, with $12.0 \%(60 / 500)$ screening positive on the GAD and 8.2\% (41/500) screening positive on the PHQ.

Table 2 summarizes demographic and behavioural characteristics across each of the screen-defined and chart-documented MMI strata. MMI was associated with female gender, lower levels of employment and income, and fewer social supports. Additionally, MMI was associated with higher levels of smoking, more frequent alcohol consumption, and higher levels of obesity.

Patients with the most active MMI accomplished the same number of, but were eligible for more, actions than their less affected counterparts (Table 3). The "detected/ active symptoms" group ( $N=99$, composite index $=36.0 \%$, $\mathrm{SD}=27.5 \%)$ had a statistically lower mean composite index than each of the other three groups $(p<0.05)$. The mean composite indices for "detected/inactive symptoms" $(N=161$, composite index $=41.7 \%, \mathrm{SD}=27.9)$, "not detected/active symptoms" $(N=75$, composite index $=41.1 \%$, $\mathrm{SD}=27.9)$, and "unaffected" $(N=425$, composite index $=45.3 \%, \mathrm{SD}=27.8$ ) groups were not statistically different from one another.

We additionally examined the six alcohol / tobacco screening, monitoring and referral components of the composite index, in terms of both eligibility for these actions (E, Table 4) and meeting these actions (M, Table 5). The presence of MMI was associated with increased

Table 3 Estimates of Composite Index by baseline screen-positive (GAD-7/PHQ-9) and chart-documented MMI

\begin{tabular}{|c|c|c|c|c|c|}
\hline & \multicolumn{4}{|c|}{ Composite Covariate (GAD, PHQ, BETTER MMI) } & \multirow[b]{2}{*}{$P$-value } \\
\hline & $\begin{array}{l}\text { Not Detected / Inactive } \\
\text { Symptoms } \\
\text { (Unaffected, } N=425 \text { ) }\end{array}$ & $\begin{array}{l}\text { Detected / Inactive } \\
\text { Symptoms }(N=161)\end{array}$ & $\begin{array}{l}\text { Not Detected / Active } \\
\text { Symptoms }(N=75)\end{array}$ & $\begin{array}{l}\text { Detected / Active } \\
\text { Symptoms }(N=99)\end{array}$ & \\
\hline \multicolumn{6}{|l|}{ Total Composite } \\
\hline Unadjusted Means & $45.3(42.6,48.0)$ & $41.7(37.4,46.1)$ & $41.1(34.7,47.6)$ & $36.0(30.5,41.5)$ & 0.02 \\
\hline Bivariate GEE ${ }^{a}$ & $43.2(36.5,49.9)$ & $40.6(33.9,47.3)$ & $40.2(32.3,48.0)$ & $32.8(25.7,39.9)$ & 0.02 \\
\hline Multivariate GEE & $43.1(36.4,49.9)$ & $41.2(34.4,48.0)$ & $41.1(33.1,49.1)$ & $34.2(26.9,41.5)$ & 0.03 \\
\hline \multicolumn{6}{|l|}{ Eligible (E) } \\
\hline Unadjusted Means & $8.8(8.5,9.0)$ & $9.1(8.6,9.6)$ & $9.1(8.4,9.8)$ & $10.3(9.6,10.9)$ & 0.0003 \\
\hline Bivariate $\mathrm{GEE}^{\mathrm{a}}$ & $8.7(8.3,9.1)$ & $9.2(8.6,9.7)$ & $9.1(8.4,9.9)$ & $10.1(9.4,10.9)$ & 0.06 \\
\hline Multivariate GEE & $8.7(8.3,9.1)$ & $9.1(8.6,9.6)$ & $9.2(8.6,9.9)$ & $10.2(9.5,11.0)$ & 0.048 \\
\hline \multicolumn{6}{|l|}{ Met (M) } \\
\hline Unadjusted Means & $3.9(3.6,4.2)$ & $3.8(3.4,4.3)$ & $3.9(3.3,4.6)$ & $3.8(3.2,4.4)$ & 0.87 \\
\hline Bivariate GEE ${ }^{a}$ & $3.7(3.2,4.3)$ & $3.8(3.2,4.6)$ & $3.9(3.1,4.9)$ & $3.4(2.7,4.3)$ & 0.45 \\
\hline Multivariate GEE ${ }^{b}$ & $3.7(3.2,4.3)$ & $3.8(3.2,4.6)$ & $4.1(3.3,5.1)$ & $3.6(2.9,4.5)$ & 0.51 \\
\hline
\end{tabular}

adjusting for clustering effect in design and single main effect

badjusting for clustering effect in design as well as age, gender and social support 
Table 4 Unadjusted Eligible (E) table for smoking and alcohol actions

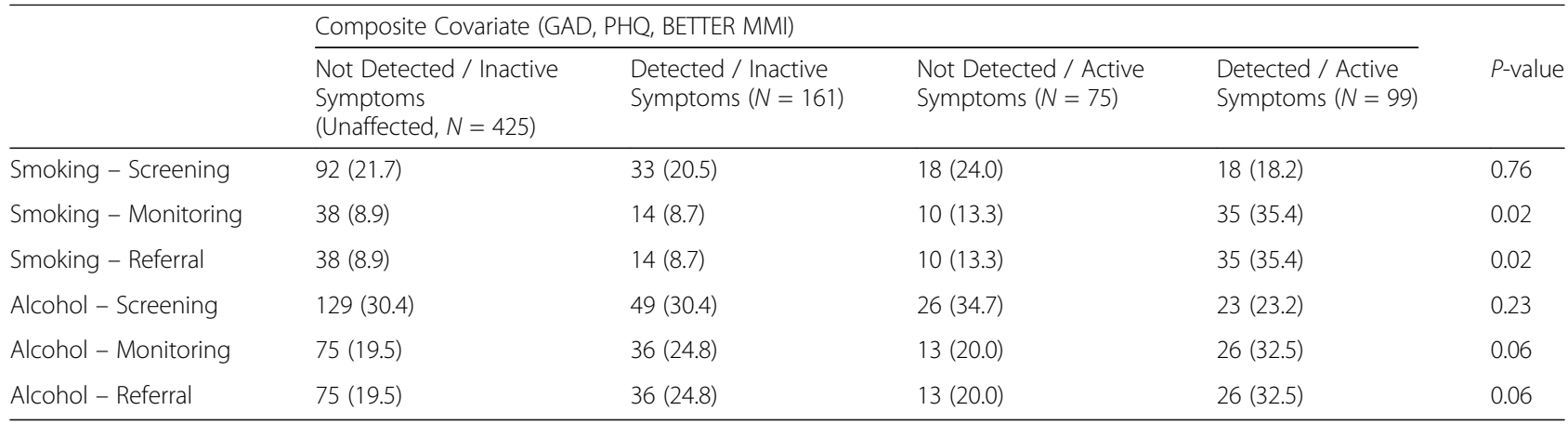

eligibility for most smoking and alcohol monitoring and referral actions. A significant difference was not observed with respect to screening actions; nor were clear differences noted with respect to meeting any actions for which patients were eligible.

\section{Discussion}

The purpose of this study was to assess potential differences in eligibility for, and adherence to, guideline based CDPS actions in patients with and without MMI. Patients with screen-positive and chart-documented MMI are eligible for more CDPS actions than their unaffected counterparts and complete a similar number of actions [20]. This suggests that the nature of MMI places patients at a health promotion disadvantage.

Of the 500 patients with available GAD and/or PHQ scores and without chart-documented MMI, 15\% (75/ 500) scored positive on the PHQ and/or GAD, supporting Craven's findings that primary care detection rates for MMI may be low [2]. However, screen positive patients without chart-documented MMI ("not detected/ active symptoms") had similar composite indices to unaffected patients. This finding fails to support more universal primary care screening for MMI as a means to improve CDPS uptake.

In contrast, patients with chart-documented MMI who screened positive on the PHQ and/or GAD ("detected/active symptoms") had lower composite indices than unaffected patients, whereas patients with chart-documented
MMI who screened negative ("detected/inactive symptoms") had similar composite indices to unaffected patients. This suggests that treatment of clinically significant MMI may have a potential impact on CDPS uptake; however, MMI treatment has yet to be confirmed in a prospective trial setting as an effective intervention for CDPS uptake.

For those patients with the highest burden of illness (detected and with active symptoms of MMI), there is increasing evidence of the cost effectiveness of interventions to promote the physical health of people with MMI [31]. Patients with MMI may particularly benefit from individualized patient-level support from a care team member, perhaps with special emphasis on health navigation and motivational interviewing as demonstrated by the BETTER trial [20]. Although screening asymptomatic patients may not be justified, we propose that primary care teams be vigilant for signs of MMI and maintain awareness of its impact on CDPS.

Our findings that MMI was associated with female gender, lower levels of employment and income, and fewer social supports are consistent with the literature [11]. Also, there is a known increased prevalence of smoking and excessive alcohol intake among patients with MMI, and vice versa [26-30]; smoking and alcohol-related CDPS uptake may be particularly affected by MMI. Teams would do well to address potential socioeconomic barriers to carrying out CDPS actions. Targeted CDPS interventions, designed with MMI-associated CDPS barriers in

Table 5 Unadjusted Met (M) table for smoking and alcohol actions ${ }^{a}$

\begin{tabular}{llllll}
\hline \multicolumn{7}{c}{ Composite Covariate (GAD, PHQ, BETTER MMI) } & & \\
\cline { 2 - 5 } & Unaffected & Detected / Inactive Symptoms & Not Detected / Active Symptoms & Detected / Active Symptoms & $P$-value \\
\hline Smoking - Screening & $60 / 92(65.2)$ & $21 / 33(63.6)$ & $12 / 18(66.7)$ & $12 / 18(66.7)$ & 0.61 \\
Smoking - Monitoring & $22 / 38(57.9)$ & $3 / 14(21.4)$ & $4 / 10(40.0)$ & $9 / 35(25.7)$ \\
Smoking - Referral & $8 / 38(21.1)$ & $4 / 14(28.6)$ & $5 / 10(50.0)$ & $11 / 35(31.4)$ & 0.046 \\
Alcohol - Screening & $72 / 129(55.8)$ & $29 / 49(59.2)$ & $9 / 26(34.6)$ & $12 / 23(52.2)$ & 0.21 \\
Alcohol - Monitoring & $44 / 75(59.5)$ & $23 / 36(74.2)$ & $7 / 13(58.3)$ & $17 / 26(70.8)$ & 0.23 \\
Alcohol - Referral & $8 / 75(10.7)$ & $5 / 36(13.9)$ & $4 / 13(30.8)$ & $6 / 26(23.1)$ & 0.27 \\
\hline
\end{tabular}

Where denominator for each cell $=$ those participants eligible (E) for each action (see Table 4) 
mind, are needed, but require evaluation of their effectiveness and relative cost prior to large scale implementation.

There exist potential limitations that should be considered when interpreting results from this study. First, as a pragmatic trial the BETTER trial employed minimal inclusion/exclusion criteria, and the demographics of the participating patients are not entirely representative of the general urban Canadian population, thus will have limited generalizability to rural, non-Caucasian, or socioeconomically disadvantaged settings. That said, the characteristics of the MMI-affected patients enrolled in this study are similar to those reported in similar literature.

Secondly, the GAD-7 and PHQ-9 are not sufficient information to confirm the diagnosis of a MMI, and rely on self-report by participants. Use of these proxies without confirmation via clinician assessment may not necessarily be the most accurate reflection of patients who are living with untreated illness.

Lastly, the study was not designed with sufficient power to demonstrate a difference in CDPS uptake on the basis of whether or not patients with evidence of MMI symptoms had come to the attention of a physician. Similarly, although trends for increased need for smoking and alcohol CDPS were seen, we were unable to confirm any clear pattern on the basis of MMI status.

\section{Conclusions}

Compared to patients unaffected by MMI, patients with documented MMI and active symptoms complete a smaller proportion of CDPS actions for which they are eligible, and are eligible for more CDPS actions overall. Primary care teams should be aware of this CDPS gap and remain vigilant for patients with active MMI in need of CDPS support. Further research is required to better understand effective approaches to CDPS in patients with MMI, and if diagnosis and treatment of MMI can improve CDPS in primary care.

\section{Abbreviations}

BETTER: Building on the existing tools to improve chronic disease prevention in family practice; CAD: Canadian dollars; CDPS: Chronic disease prevention and screening; E: Eligible actions; EMR: Electronic medical record; GAD: Generalized anxiety disorder; GEE: Generalized estimating eq.; M: Met actions; MMI: Moderate mental illness; PHQ: Patient health questionnaire; REB: Research ethics board

\footnotetext{
Acknowledgements

The authors wish to thank the BETTER trial investigative team and prevention practitioners who administered the intervention and collected data used for this study. Thank you also to Carolina Aguilar for her assistance in preparing this manuscript for publication.
}

\section{Funding}

This research was made possible through a financial contribution from the Canadian Partnership Against Cancer and Health Canada and supported by the Heart and Stroke Foundation of Ontario Grant No. PG 10-0479. Dr. Grunfeld is supported by a clinician scientist award from the Ontario Institute for Cancer Research (OICR) with funds from the Ontario Ministry of Research and Innovation (MRI). The opinions, results, and conclusions reported are those of the authors and are independent from the funding sources and no endorsement by $\mathrm{OICR}$ or MRI is intended or should be inferred.

\section{Availability of data and materials}

The datasets generated during and/or analyzed during the current study are not publicly available due to ongoing analysis and planned publications but are available from the corresponding author on reasonable request.

\section{Authors' contributions}

All authors have read and approved of the final manuscript. GS oversaw the design and interpretation of this secondary analysis and oversaw manuscript writing. CM conducted all statistical analyses, prepared all data for inclusion in the manuscript, and provided manuscript edits. RM contributed to statistical analyses and provided manuscript edits. EG assisted with interpretation of this secondary analysis and provided manuscript edits. DM assisted with the design and interpretation of this secondary analysis and provided substantive edits to the manuscript.

\section{Authors' information}

GS is an Associate Professor with the University of Alberta Department of Family Medicine, and a member of the Clinical Working Group for the BETTER trial investigative group.

$\mathrm{CM}$ is a biostatistician with the University of Toronto Department of Family and Community Medicine and the BETTER trial investigative group.

RM is a senior biostatistician with the University of Toronto Department of Family and Community Medicine and the BETTER trial investigative group. EG is a Professor with the University of Toronto Department of Family and Community Medicine, and is a co-principal investigator for the BETTER trial investigative group.

DM is an Associate Professor with the University of Alberta Department of Family Medicine, and is a co-principal investigator for the BETTER trial investigative group.

\section{Competing interests}

The authors declare that they have no competing interests.

\section{Consent for publication}

Not applicable.

\section{Ethics approval and consent to participate}

The BETTER trial was approved by the Ontario Cancer Research Ethics Board (file \#10-024), University of Alberta Health Research Ethics Board

(Pro00010126), and all relevant research ethics boards in each province and at each primary care team site. All patients provided written informed consent to participate in the BETTER trial.

\section{Publisher's Note}

Springer Nature remains neutral with regard to jurisdictional claims in published maps and institutional affiliations.

Received: 13 October 2016 Accepted: 9 June 2017

Published online: 17 June 2017

\section{References}

1. World Health Organization., World Organisation of National Colleges Academies and Academic Associations of General Practitioners/Family Physicians. Integrating mental health into primary care: a global perspective. Geneva, Switzerland, London: World Health Organization; Wonca; 2008.

2. Craven MA, Bland R. Depression in primary care: current and future challenges. Can J Psychiatry. 2013;58(8):442-8.

3. Katz SJ, Kessler RC, Lin E, Wells KB. Medication management of depression in the United States and Ontario. J Gen Intern Med. 1998;13(2):77-85.

4. Williams JW Jr, Rost K, Dietrich AJ, Ciotti MC, Zyzanski SJ, Cornell J. Primary care physicians' approach to depressive disorders. Effects of physician specialty and practice structure. Arch Fam Med. 1999;8(1):58-67.

5. Houle J, Beaulieu MD, Lesperance F, Frasure-Smith N, Lambert J. Inequities in Medical Follow-Up for Depression: A Population-Based Study in Montreal. Psychiatr Serv. 2010;61(3):258-63.

6. Ostbye T, Yarnall KS, Krause KM, Pollak Kl, Gradison M, Michener JL. Is there time for management of patients with chronic diseases in primary care? Ann Fam Med. 2005;3(3):209-14. 
7. Yarnall KS, Pollak Kl, Ostbye T, Krause KM, Michener JL. Primary care: is there enough time for prevention? Am J Public Health. 2003;93(4):635-41.

8. Linzer M, Bitton A, Tu SP, Plews-Ogan M, Horowitz KR, Schwartz MD. Association of C, Leaders in General Internal Medicine Writing G, Poplau S, Paranjape A et al: The End of the 15-20 Minute Primary Care Visit. J Gen Intern Med. 2015;30(11):1584-6.

9. Raffoul M, Moore M, Kamerow D, Bazemore A. A Primary Care Panel Size of 2500 Is neither Accurate nor Reasonable. J Am Board Fam Med. 2016;29(4):496-9.

10. Health FPaTACOP. Toward a healthy future: second report on the health of Canadians. Ottawa, ON: Minister of Public Works and Government Services Canada; 1999.

11. Allen J, Balfour R, Bell R, Marmot M. Social determinants of mental health. Int Rev Psychiatry. 2014;26(4):392-407.

12. Canadian Medical Association. Health care in Canada: what makes us sick? 2013. Available at https://www.cma.ca/Assets/assets-library/document/fr/ advocacy/What-makes-us-sick_en.pdf

13. Zgibor JC, Songer TJ. External Barriers to Diabetes Care: Addressing Personal and Health Systems Issues. Diabetes Spectrum. 2001;14(1):23-8.

14. Burack RC. Barriers to clinical preventive medicine. Prim Care. 1989;16(1):245-50

15. Druss BG, Rosenheck RA, Desai MM, Perlin JB. Quality of preventive medical care for patients with mental disorders. Med Care. 2002;40(2):129-36.

16. Egede $L E$, Grubaugh $A L$, Ellis $C$. The effect of major depression on preventive care and quality of life among adults with diabetes. Gen Hosp Psychiatry. 2010;32(6):563-9.

17. Campbell-Scherer D, Rogers J, Manca D, Lang-Robertson K, Bell S, Salvalaggio G, et al. Guideline harmonization and implementation plan for the BETTER trial: Building on Existing Tools to Improve Chronic Disease Prevention and Screening in Family Practice. CMAJ open. 2014;2(1):E1-E10.

18. Smetanin P, Briante C, Stiff D, Ahmad S, Khan M, Mental Health Commission of Canada, RiskAnalytica (Firm). The life and economic impact of major mental illnesses in Canada. 2011. Available at http://www.mentalhealthcommission.ca/ sites/default/files/MHCC_Report Base_Case_FINAL_ENG 0 0.pdf.

19. Wong ST, Manca D, Barber D, Morkem R, Khan S, Kotecha J, et al. The diagnosis of depression and its treatment in Canadian primary care practices: an epidemiological study. CMAJ Open. 2014;2(4):E337-42.

20. Grunfeld E, Manca D, Moineddin R, Thorpe KE, Hoch JS, Campbell-Scherer $D$, et al. Improving chronic disease prevention and screening in primary care: results of the BETTER pragmatic cluster randomized controlled trial. BMC Fam Pract. 2013;14(1):175.

21. Spitzer RL, Kroenke K, Williams JB, Lowe B. A brief measure for assessing generalized anxiety disorder: the GAD-7. Arch Intern Med. 2006;166(10):1092-7.

22. Herr NR, Williams JW Jr, Benjamin S, McDuffie J. Does this patient have generalized anxiety or panic disorder?: The rational clinical examination systematic review. JAMA. 2014;312(1):78-84.

23. Manea L, Gilbody S, McMillan D. Optimal cut-off score for diagnosing depression with the Patient Health Questionnaire (PHQ-9): a meta-analysis. CMAJ. 2012;184(3):E191-6.

24. Kroenke K, Spitzer RL, Williams JB. The PHQ-9: validity of a brief depression severity measure. J Gen Intern Med. 2001;16(9):606-13.

25. Nietert PJ, Wessell AM, Jenkins RG, Feifer C, Nemeth LS, Ornstein SM. Using a summary measure for multiple quality indicators in primary care: the Summary QUality InDex (SQUID). Implement Sci. 2007;2:11.

26. Hasin DS, Goodwin RD, Stinson FS, Grant BF. Epidemiology of major depressive disorder: results from the National Epidemiologic Survey on Alcoholism and Related Conditions. Arch Gen Psychiatry. 2005:62(10):1097-106.

27. Dierker LC, Avenevoli S, Stolar M, Merikangas KR. Smoking and depression: an examination of mechanisms of comorbidity. Am J Psychiatry. 2002;159(6):947-53.

28. Sullivan LE, Goulet IL, Justice AC, Fiellin DA. Alcohol consumption and depressive symptoms over time: A longitudinal study of patients with and without HIV infection. Drug Alcohol Depend. 2011;117(2-3):158-63.

29. Fuehrlein BS, Mota N, Arias AJ, Trevisan LA, Kachadourian LK, Krystal JH, et al. The burden of alcohol use disorders in US military veterans: results from the National Health and Resilience in Veterans Study. Addiction. 2016; 111(10):1786-94

30. Lawrence D, et al. Smoking, mental illness and socioeconomic disadvantage: analysis of the Australian National Survey of Mental Health and Wellbeing. BMC Public Health. 2013;13:462. doi:10.1186/1471-2458-13-462.

31. Park AL, McDaid D, Weiser P, Von Gottberg C, Becker T, Kilian R, et al. Examining the cost effectiveness of interventions to promote the physical health of people with mental health problems: a systematic review. BMC Public Health. 2013;13:787.

\section{Submit your next manuscript to BioMed Central and we will help you at every step:}

- We accept pre-submission inquiries

- Our selector tool helps you to find the most relevant journal

- We provide round the clock customer support

- Convenient online submission

- Thorough peer review

- Inclusion in PubMed and all major indexing services

- Maximum visibility for your research

Submit your manuscript at www.biomedcentral.com/submit
Biomed Central 